\title{
LUT
}

University

\section{Comparison of the Performance of Different Asynchronous Solid-Rotor Constructions in a Megawatt-Range High-Speed Induction Motor} Kurvinen Emil, Di Chong, Petrov llya, Jastrzebski Rafal, Kepsu Daria, Pyrhönen

This is a Final draft version of a publication

published by IEEE

in 2019 IEEE International Electric Machines \& Drives Conference (IEMDC)

DOI: $10.1109 /$ IEMDC.2019.8785288

Copyright of the original publication: (C) 2019 IEEE

Please cite the publication as follows:

Kurvinen, E., Di, C., Petrov, I., Jastrzebski, R. P., Kepsu, D., \& Pyrhönen, J. (2019, May). Comparison of the Performance of Different Asynchronous Solid-Rotor Constructions in a Megawatt-Range High-Speed Induction Motor. In 2019 IEEE International Electric Machines \& Drives Conference (IEMDC) (pp. 820-825). IEEE.

(c) 2019 IEEE. Personal use of this material is permitted. Permission from IEEE must be obtained for all other uses, in any current or future media, including reprinting/republishing this material for advertising or promotional purposes, creating new collective works, for resale or redistribution to servers or lists, or reuse of any copyrighted component of this work in other works.

This is a parallel published version of an original publication. This version can differ from the original published article. 


\section{Comparison of the Performance of Different Asynchronous Solid-Rotor Constructions in a Megawatt-Range High-Speed Induction Motor}

\author{
Emil Kurvinen \\ Department of Mechanical Engineering \\ LUT School of Energy Systems \\ Lappeenranta-Lahti University of Technology \\ Lappeenranta, Finland \\ emil.kurvinen@lut.fi
}

\author{
Chong Di, Ilya Petrov, Rafal P. Jastrzebski, \\ Daria Kepsu, Juha Pyrhönen \\ Department of Electrical Engineering \\ LUT School of Energy Systems \\ Lappeenranta-Lahti University of Technology \\ Lappeenranta, Finland \\ chong.di@lut.fi, ilya.petrov@lut.fi, rafal.jastrzebski@lut.fi, \\ daria.kepsu@lut.fi, juha.pyrhonen@lut.fi
}

\begin{abstract}
High-speed electrical machines have their advantages, such as higher power density than in traditional electrical machines, and disadvantages, such as very demanding and tailored design and manufacturing process. The manufacturing of the rotor for a high-speed electrical machine is extra complex. In a high-speed electrical machine, the rotor in normal operation experiences various types of loadings, such as centrifugal forces from the rotation, temperature gradients from the operational environment, losses generated in the electrical machine and loads from the process. A failure related to the mechanical integrity of a rotor leads to a halt and very probably to the complete malfunction of the machine. The aim of this study is to compare three different rotor constructions in a high-speed induction electrical machine operating at the megawatt power range. The first one is a full copper squirrel cage rotor that consists of 25 pieces ( 22 copper bars, two copper end rings and a steel shaft), the second is a slitted solid rotor with copper end rings that consists of three pieces and two materials, and the third is a slitted solid rotor made solely of structural steel consisting of one piece. Further, these rotors are compared in terms of their electromagnetic performance, applying the same stator structure. The manufacturing challenges are directly related to the number of individual parts needed for the construction of the full rotor. The base material for the rotor core of the studied high-speed induction machine is often structural steel that is magnetically soft, has moderate electrical resistivity, and can be combined with copper or aluminum cage winding which is non-magnetic and has high electrical conductivity. From the mechanical perspective, these materials are very different; e.g. high-strength copper (CuCrZr) has a $50 \%$ higher thermal expansion coefficient, $13 \%$ higher density, $600 \%$ higher thermal conductivity, and approximately $50 \%$ lower yield strength than common structural steel (S355). This complicates the rotor manufacturing, as the required tolerances for the assembly of the rotor components are very strict and depend on the final manufacturing method of the rotor.
\end{abstract}

Index Terms - high-speed induction machine (IM), manufacturing, megawatt range, rotor construction

\section{INTRODUCTION}

High-speed electrical machines have been actively researched for decades, and several different high-speed machine topologies have been developed. [1] The potential positive effect of the increased rotational speed and consequently increased power density leads to an appealing development direction, i.e., physically smaller electrical machines can provide similar or even better performance than currently available traditional machines in bulky size especially when applying them to high-speed applications using a very bulky and lossy step-up gear. The possible improvements compared to standard machines are significant. The awareness of energy utilization has led to increasing usage of frequency converter supplied machines, and further utilizing more tailored machines for a specific purpose, i.e., turbo-machinery applications [2] or natural gas compression applications [3].

High-speed induction machines have proven to be suitable for many applications. [4] The magnetic core of a rotor in induction machine can be constructed from a laminated structure or directly from single solid piece. Laminated rotor could be utilized in induction machines with the surface velocity maximum of $200 \mathrm{~m} / \mathrm{s}$. [5]. In this study, the surface velocity of the studied rotor structures is $156 \mathrm{~m} / \mathrm{s}$ so the laminated structure should in principle be possible. However, as the power of the studied motor is up to megawatt range this brings extra challenges in reliable design and manufacturing of a laminated rotor structure considering its active length, diameter and overall length of the shaft. The active part of a solid-rotor induction electrical machine is often constructed from one of three different types. First, a solid rotor with a squirrel cage made, e.g., from copper or aluminum leads to good electromagnetic performance but to a much more challenging manufacturing process for high-speed purposes, as the rotor contains several different parts with individual tolerances that are assembled together. This leads to a relatively low mechanical rigidity and lower confidence due to noticeable manufacturing variation between different rotors. Second, a slitted solid rotor leads to a slightly lower electromagnetic performance but higher mechanical strength compared to a full squirrel-cage rotor. The slitted rotor can also comprise copper end rings that significantly reduce the total rotor resistance 
and therefore the slip of the rotor. Slits in the rotor enable better flux flow through the rotor. The copper end rings can be banded with a high strength material to increase the structural strength. The third is a smooth solid rotor, which leads to poor electromagnetic performance but high mechanical strength. [3] The aim of the study is to compare these three different rotor structures and investigate their actual performance in a megawatt range electric motor application.

Designing high-speed machines is in general a complex process due to its highly iterative nature. The design process of an induction machine generally follows similar steps as that of a high-speed two-pole permanent magnet synchronous machine (PMSM) [6]. The design and analysis of a high-speed machine includes bearing, dynamic, electrical, mechanical, structural, seals and thermal designs and analyses and for an application, e.g., compressor it requires the impeller design, too. These individual tasks are highly connected, and to achieve the best possible performance for the machine, certain compromises are needed from all participants.

The design group consists of experts from several fields who all need to be taken into account in the realization of the actual motor design. This is often very challenging, as different machine components are manufactured of different materials such as specific steel, copper and aluminum alloys, which are manufactured with specific tolerances. Further, they require high strength metallic bonding or form-base fixing between them to tolerate the loads caused by a high rotation speed. Due to the floating parameters, such as tolerances, internal material structure and material connection, each component is an individual and the structural strength and dynamic behavior becomes difficult to predict. For example, the generally used ISO 268-2 specifies tolerances for shafts and holes. A shaft with a rated diameter of $250 \mathrm{~mm}$ with basic $\mathrm{h} 7$ tolerance may be manufactured from $249.48 \mathrm{~mm}$ to $250 \mathrm{~mm}$, actually. Also ISO 2768 standard which defines general tolerances for linear and angular dimensions. It is divided into four tolerance classes, of which "fine" is the most precise. Between 30 $\mathrm{mm}$ to $120 \mathrm{~mm}$ dimensions this standard allows $+/-0.15 \mathrm{~mm}$ difference in the actual manufactured parts. This variation leads to challenges when joining separate parts together, e.g. in case of squirrel caged rotor. This leads to the fact that the first manufactured high-speed machine contains several factors that increase the risk of failure. The rotor structure is designed so that different parts withstand the mechanical stresses and keep their rigidity even in the worst operational conditions. The design process is fairly well known, but additional challenges arise from demanding manufacturing techniques. There are different techniques to manage the rotor rigidity when different materials are used, such as designing the active part in a way that the copper bars or pipes are embedded in the rotor core or joint to open slots in rotor with brazing [7], hot isostatic pressing (HIP) [8], explosion welding (EXW) [9] or premanufactured bimetals.

Lowering the risks that a prototype machine rotor has a manufacturing error is important, especially in the very first revision number. A case study with three different rotor con- structions is reported and their electromagnetic performance analyzed. A megawatt sized induction machine supported with active magnetic bearings (AMB) is under focus. Table I depicts the studied structures and the number of individual parts.

TABLE I

STUDIED ROTOR CONSTRUCTIONS AND NUMBER OF INDIVIDUAL PARTS RELATED TO THE STRUCTURES

\begin{tabular}{|l|l|l|}
\hline Case & Description & Number of parts \\
\hline Case 1 & Cu squirrel caged rotor & 25 pieces \\
Case 2 & Cu short-circuit rings, slitted core & three pieces \\
Case 3 & Solid slitted rotor with Fe end rings & one piece \\
\hline
\end{tabular}

The rotor construction can be varied depending on the required mechanical manufacturability and performance of the machine. The number of individual components in a complex structure categorizes the rotor constructions where the copper end rings and copper bars form a squirrel cage induction machine (case 1). The second construction consists of a slitted solid rotor with copper end rings. This construction refers to a medium complexity structure (case 2). The third construction consists of a structural steel slitted rotor that refers to a simple structure (case 3). The purpose of the rotor structure variation is to analyze the rotor made of copper bars integrated into the rotor core and to compare it with a rotor made only of a machined steel slitted active part. The aim of the study is to investigate the selection of different active rotor parts and their consequent effects on the machine performance. Highspeed machines and their commissioning involve many risks and potential pitfalls. Naturally, a simpler rotor structure is appealing to decrease the risks, especially in the first prototype.

\section{CASES STUDIED}

The case study is based on a full squirrel cage induction electrical machine. The machines rated capacity is $2 \mathrm{MW}$ at $12000 \mathrm{~min}^{-1}(200 \mathrm{~Hz})$ and it is operated with a $660 \mathrm{~V}$ three phase supply. In the case of this high-speed induction rotor, the copper experiences high temperatures and high rotational speeds. Load cycles cause fatigue loading on the copper, and a safety factor needs to be included so that the yield strength is not exceeded. Fig. 1 and Fig. 2 depicts the outlook of the rotor with a full copper squirrel cage (case 1). The end ring is embedded in the construction to make its stresses lower.

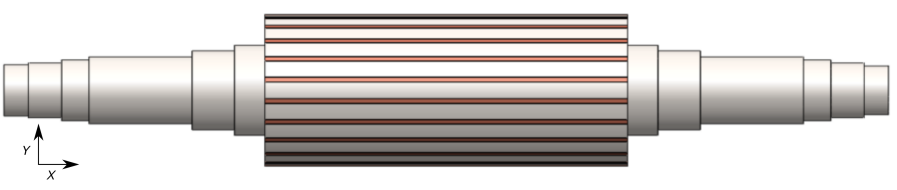

Fig. 1. Layout of the copper squirrel cage rotor (side view). The copper end rings are not seen as they are embedded in the construction (see Fig.2).

Three lowest free-free frequencies of the rotor are $319 \mathrm{~Hz}$, $656 \mathrm{~Hz}$ and $1171 \mathrm{~Hz}$. With a $5 \mathrm{MN} / \mathrm{m}$ bearing stiffness and $10.5 \mathrm{~kg}$ coupling at the drive end, the first bending mode occurs at $18640 \mathrm{~min}^{-1}$ (backward whirling mode) and 19 $830 \mathrm{~min}^{-1}$ (forward whirling mode). The rotors studied have 


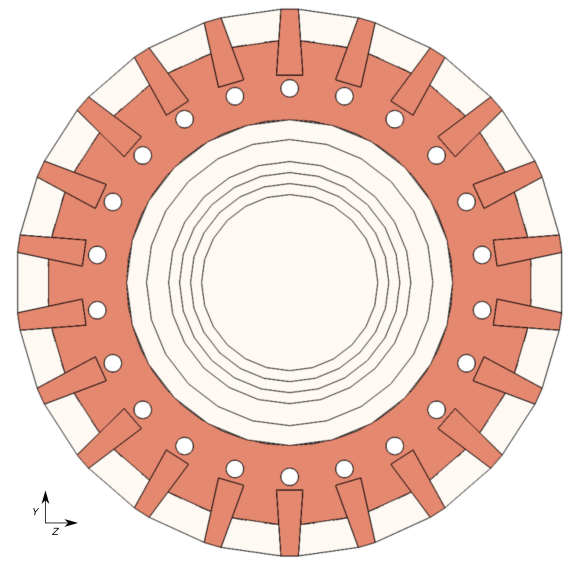

Fig. 2. Layout of the copper squirrel cage rotor (view from axial end) scaled 4:1 compared to Fig. 1 .

very similar rotor bending frequencies. However, the torsional stiffness of the slitted rotor is clearly lower compared to the squirrel caged rotor [10]. The inner diameter of the copper end ring is $148 \mathrm{~mm}$, and its outer diameter is $220 \mathrm{~mm}$. At the nominal speed, the copper experiences tangential stress of $155 \mathrm{MPa}$ and radial stress of $8 \mathrm{MPa}$ with a copper density of $8930 \mathrm{~kg} / \mathrm{m}^{3}$ and a Poissons ratio of 0.343 . With chromium zirconium copper $(\mathrm{CuCrZr})$, the yield strength is $350 \mathrm{MPa}$. However, due to the fatigue of loads and uncertainty in joining the copper to steel, approximately half of the yield stress is considered the maximum allowed (175 MPa), thus becoming a limiting factor for utilization. The situation could be improved by adding a high strength band on top of the copper end ring. However, additional materials also affect the performance of the electrical machine and the increase number of connected parts.

When designing a solid-rotor machine one of the most important tasks is to mitigate harmonic losses on the rotor surface. Both stator current linkage harmonics and permeance harmonics caused by slot openings cause rotor losses. Therefore, the means to mitigate harmonic losses include minimization of the harmonic amplitudes in the air gap. This can be done by selecting as high stator slot number as possible which reduces the current linkage harmonics and to try to eliminate the permeance variations caused by the slot openings. Semimagnetic slot wedges are an efficient means of mitigating the slot harmonics. Also the rotor construction itself may have an impact on the rotor surface losses. Especially, in case of a slitted rotor, skewing may mitigate some of the harmonic losses. In the motor studied the number of stator slots was selected only 18 because of the manufacturing challenges related to the stator winding. However, already this number of stator slots avoids an extensive value of the harmonic losses generated on the rotor surface especially when the stator has a short pitched winding.

Table II depicts the electrical machine parameters and Table III depicts the operational performance for a squirrel-cage rotor (case 1).
TABLE II

HARMONIC COMPONENTS OF THE AIR-GAP FLUX DENSITIES, PER-UNIT SLIP AND ROTOR FREQUENCIES IN THE STUDIED CASES.

\begin{tabular}{|l|l|}
\hline Parameter & Value \\
\hline Stator stack iron length [mm] & 538 \\
Stator stack iron outer diameter [mm] & 550.5 \\
Stator stack iron inner diameter [mm] & 260.5 \\
Rotor outer diameter [mm] & 248.5 \\
Rotor tangential tension (at rated torque) $[\mathrm{kPa}]$ & 31 \\
Number of stator slots & 18 \\
Effective coil-turns in the slot & 2 \\
Number of stator parallel branches & 1 \\
Stator coil-turns per phase in series & 6 \\
Single coil copper area $\left(k_{\mathrm{Cu}}=0.45\right)\left[\mathrm{mm}^{2}\right]$ & 335 \\
Winding type: Distributed, $Q_{\mathrm{s} / \mathrm{mp}}$ & 3 \\
Number of pole-pairs & 1 \\
Winding connection & $\mathrm{Star}$ \\
Stator core material & $\mathrm{M} 270-35$ \\
Rotor core material & $\mathrm{S} 355$ \\
\hline
\end{tabular}

TABLE III

OPERATIONAL PERFORMANCE FOR A SQUIRREL CAGED ROTOR (CASE 1).

\begin{tabular}{|l|l|}
\hline Parameter & Value \\
\hline Rated speed $n_{\mathrm{N}}\left[\mathrm{min}^{-1}\right]$ & 12000 \\
Rated frequency $f_{\mathrm{sN}}[\mathrm{Hz}]$ & 200 \\
Rated mechanical power $P_{\mathrm{N}}[\mathrm{kW}]$ & 2000 \\
Rated torque T [Nm] & 1600 \\
Rated apparent input power $S_{\mathrm{N}}[\mathrm{kVA}]$ & 3100 \\
Rated terminal phase voltage $U_{\mathrm{phN}}\left[V_{\mathrm{rms}}\right]$ & 660 \\
Rated stator phase supply current $I_{\mathrm{sN}}\left[A_{\mathrm{rms}}\right]$ & 2100 \\
Phase resistance $R_{\mathrm{ph}}[\mathrm{Ohm}]$ & 0.0011 \\
Power factor $\cos \phi$ at rated operating point & 0.7 \\
Estimated efficiency at the nominal load $[\%]$ & 96 \\
Current density (with copper space factor 0.45$)\left[\mathrm{A} / \mathrm{mm}^{2}\right]$ & 4.5 \\
\hline
\end{tabular}

Electromagnetic calculations were performed with 2D Finite-element method (FEM). 2D FEM simulation cannot directly take into account lack of copper end ring for case 3. Thus it is appended with the analytical calculation according to [4], which suggests that the rotor resistance should be increased in this case by a factor of 1.73. Fig. 3 depicts the cases studied.

The rotor outer diameter in the electrical machine active part is $284.5 \mathrm{~mm}$ and is kept constant for all of the cases studied. The slit depth was varied according to [11], and the minimum rotor losses were experienced at a depth of $55 \mathrm{~mm}$. Thus, $55 \mathrm{~mm}$ slits were selected for the cases studied. In cases 2 and 3, the same slit depth is used. In case 1, the copper squirrel cage is formed from 22 copper bars. The copper end rings in cases 1 and 2 are $30 \mathrm{~mm}$ thick, with a $120 \mathrm{~mm}$ inner diameter and $184.5 \mathrm{~mm}$ outer diameter. The end ring is connected to the shaft in order to decrease the stresses that the end ring experiences during operation. The outer diameter is limited in order to decrease the stresses that the copper end ring experiences. 

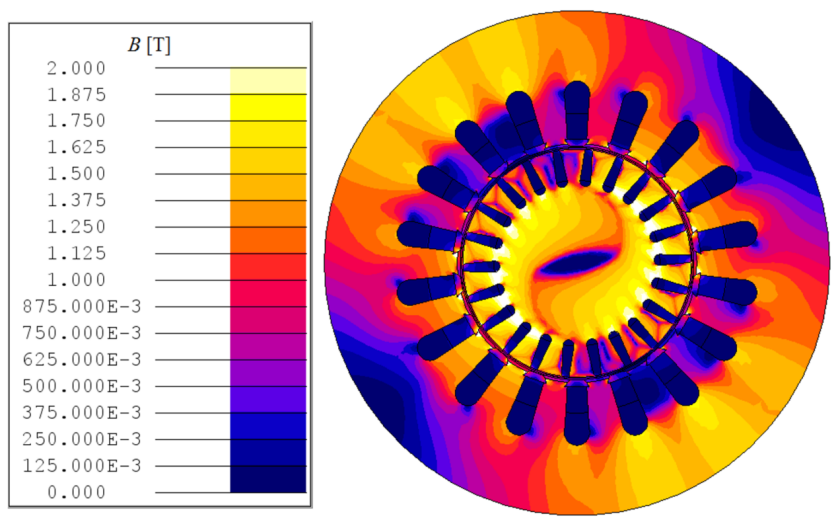

Case 1: Copper squirrel cage
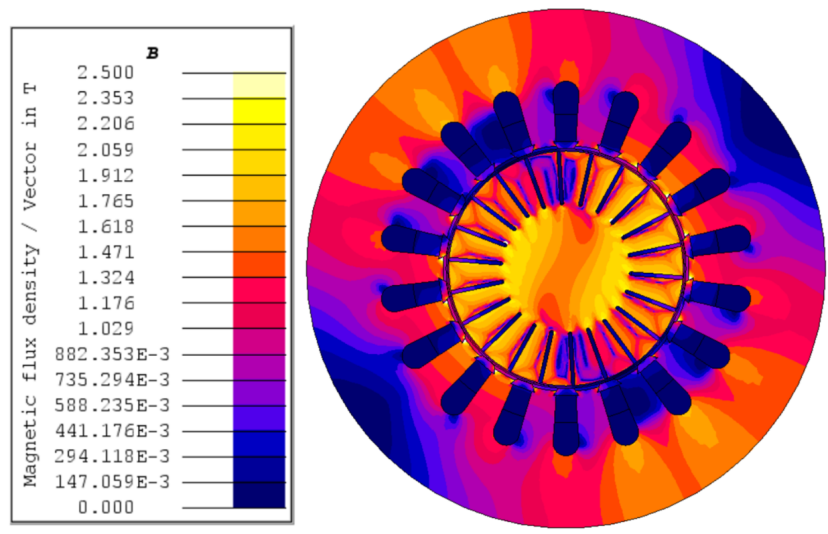

Case 2: Slitted with copper end rings
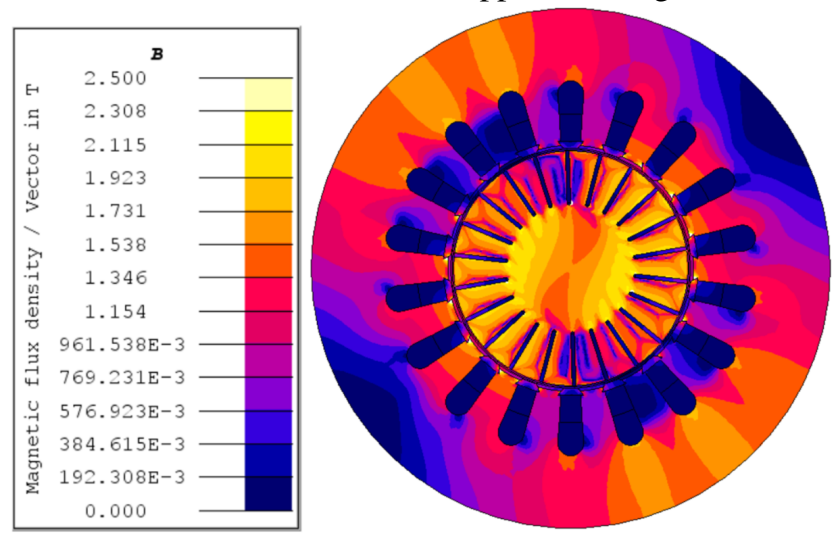

Case 3: Slitted without copper end rings

Fig. 3. Electric machine topologies studied.

\section{RESUltS}

The power density of the machines are almost constant, as all the machines are operating at $1600 \mathrm{Nm}$ and the volume is almost the same in the machines. The power factor estimated from the 2D analysis for case 1 is 0.697 and for cases 2 and 3 it is 0.675 . Comparison of the air-gap flux density harmonic components for different cases is shown in Table IV. Lower stator slot harmonic amplitude is more acceptable as it causes a smaller rotor harmonic eddy-current loss.

Case 1 creates the minimum slip related losses (fundamental harmonic losses) as Case 1 has the lowest per-unit slip,
TABLE IV

HARMONIC COMPONENTS OF THE AIR-GAP FLUX DENSITIES, PER-UNIT SLIP AND ROTOR FREQUENCIES IN THE STUDIED CASES.

\begin{tabular}{|l|l|l|l|}
\hline Parameters & Case 1 & Case 2 & Case 3 \\
\hline Fundamental, $[\mathrm{T}]$ & 0.936 & 0.931 & 0.932 \\
$17^{\text {th }}$ harmonic, ${ }^{*}[\mathrm{~T}]$ & 0.076 & 0.082 & 0.087 \\
$19^{\text {th }}$ harmonic, ${ }^{*}[\mathrm{~T}]$ & 0.033 & 0.037 & 0.039 \\
Per-unit slip $s$ & 0.0013 & 0.0028 & 0.0049 \\
Rotor frequency $s_{\mathrm{f}}, \mathrm{Hz}$ & 0.26 & 0.56 & 0.98 \\
\hline & ${ }^{\text {th }}$ and $19^{\text {th }}$ harmonics are the $1^{\text {st }}$ order stator slot harmonics.
\end{tabular}

whereas in contrast Case 3 creates the maximum slip related losses. In addition, because Case 3 has the maximum stator slot harmonics ( $17^{\text {th }}$ harmonic 0.087 and $19^{\text {th }}$ harmonic 0.039$)$, it generates the maximum harmonic losses on the rotor side.

Table $\mathrm{V}$ shows the losses in the copper squirrel-caged rotor (case 1) and the slitted rotor with copper end rings (case 2) and without copper end rings (case 3). A sinusoidal supply was used (converter harmonics are not included) and iron losses were estimated by using the Bertotti method in FEM.

TABLE V

LOSS COMPARISON OF THE STUDIED CASES.

\begin{tabular}{|l|c|c|c|}
\hline \multicolumn{1}{|c|}{ Loss type } & Case 1 & Case 2 & Case 3 \\
\hline Copper losses (stator resistive losses) [kW] & 8 & 8.7 & 8.7 \\
Iron losses (stator stack) [kW]* & 27.2 & 26.8 & 26.8 \\
Iron losses (solid rotor) [kW]* & 24.7 & 39.6 & 40.5 \\
Copper bars losses [kW]* & 7 & - & - \\
Extra losses [kW]** & 10 & 10 & 10 \\
Total electromagnetic losses [kW] & 76.9 & 85.1 & 86 \\
\hline Electromagnetic efficiency [ \%] & $96.16 \%$ & $95.75 \%$ & $95.70 \%$ \\
\hline *Estimated with FEM ** 0.5 \% of the nominal load [12]
\end{tabular}

\section{DISCUSSION}

The aim of this study is to compare the performance of different rotor constructions taking the manufacturing complexity and structural rigidity into consideration. The machines physical dimensions were kept the same, with the exception that in Case 3, the copper end rings were removed and rotor was made same length of the same core material as the length with copper end rings are. In a high-speed induction machine with a copper squirrel cage, the machine can have lower slip-related rotor losses and consequently a higher efficiency. However, it is rational to check the electromagnetic performance of the machine also with simpler rotor constructions, as it greatly simplifies the rotor manufacturing procedure, and with certain general machine parameters (e.g. number of slots, open slot width, rotational speed, conductivity of the rotor core steel, etc.), it might yield nearly similar machine performance.

Case 3 was the most straightforward, as the rotor could be manufactured from a single solid steel piece with a lathe, milling machine and grinding machine. Case 2 can also be manufactured with the same technique as Case 3 with the addition of making two copper end rings and connecting those to the solid shaft, e.g., with vacuum brazing or electron beam welding. The connection of two different metals, especially copper and steel, requires specific knowledge of metallurgy and additional manufacturing steps prior to commissioning. 
In Case 2, the copper ring can be attached in the radial and axial directions, and the dimensions of the copper end rings are fairly small, i.e., the stresses induced by the difference in the thermal expansion coefficient can be withstood without exceeding the materials yield strength. In Case 1, the number of individual pieces increases as 22 copper bars need to be inserted into the structure to manufacture a complete copper squirrel cage. For this structure, the manufacturing becomes more challenging compared to Case 2. The 22 copper bars should be attached mechanically rigidly enough to the rotor core, and galvanic connections with the copper end rings should be achieved to build an intact squirrel cage that carries most of the rotor electric currents. The copper bars can be inserted, e.g., inside the rotor core, and the core steel can hold them in place during operation. This can be achieved by using cannon drilling, designing a suitable shape for the copper bars and rotor slots so that the shape will hold the bars in place, or joining them to the slot for example with vacuum brazing. As can be seen, from the manufacturing perspective Case 3 is the most appealing, Case 2 is the second most appealing, and Case 1 with its full copper squirrel cage rotor is the least appealing.

\section{A. The effect of the rotor construction on active magnetic bearing design}

From the AMB design point of view, even small differences in machine topologies can cause different spatial harmonics of flux density in the airgap. Various effects such as harmonics of magnetizing current, saturation of teeth, slot shapes, edge saturation, eddy currents, and winding connections will cause variations of permeability in the stator and rotor and nonsymmetrical flux density. These with rotor displacement will result in unbalanced magnetic pull (UMP) that has effect on levitation control.

The control algorithm of AMBs has to take into account the magnetic force caused by the eccentricity. The maximum force produced by an AMB has to overcome the sum of, the gravity force, UMP force, mass unbalance forces, negative stiffness effects of bearings, and other disturbance forces (e.g. from the process). At the same time the controller has to ensure that no structural resonances of the rotor and frame are excited. In case of static forces, the typical safety limit is such that the AMB force should be three to four times the maximum total load force in the nominal point. The AMB system by injecting a direct current should compensate for the direct component of the magnetic force and alternating current can be used to compensate for the rotating UMP. The operational range defined by the size of the retainer bearings has to be considered as AMB force capacity will decrease while UMP will increase as a function of the rotor displacement.

With simple modelling, the rotor eccentricity, can be classified as static, dynamic or mixed [13]. The rotor eccentricity introduces UMP, extra noise, vibration, and losses. The squirrel copper cage rotor could result in the biggest value of the UMP. For static eccentricity, UMP can be predicted analytically [14].

\section{B. Electromagnetic performance of studied cases}

From the electromagnetic point of view, the copper squirrel cage has the lowest losses because it runs with the lowest slip. However, also this rotor suffers from losses caused by the air gap harmonics in the solid rotor core. Actually, these losses are the dominating ones, and means for mitigating the harmonic losses must be exercised. The losses are greater in the slitted rotor cases (2 and 3). The harmonic losses in the rotor core remain roughly at the same level in these cases. Actually, slitting may even help in reducing the harmonic losses. In the case of the slitted rotors, the copper losses in the stator increase from $8 \mathrm{~kW}$ to $8.7 \mathrm{~kW}$ because of the weaker rotor power factor, so more stator currents are needed to induce the flux in the rotor. The iron losses in the stator decrease from $27.2 \mathrm{~kW}$ to $26.8 \mathrm{~kW}$ because of the narrower rotor slot opening, which results in lower stator harmonic core losses. In the actual machine, the stator is liquid cooled and the stator coils are also directly cooled so that the increase of the stator losses can be relatively easily handled with the applied cooling system.

The rotor losses are also increased from $31.2 \mathrm{~kW}(24.7 \mathrm{~kW}$ iron losses and $7 \mathrm{~kW}$ copper bar losses) in Case 1 to $39.6 \mathrm{~kW}$ (27\% higher) in Case 2 and $40.5 \mathrm{~kW}$ (30\% higher) in Case 3 . The increased rotor losses are due to the increased rotor resistance as steel electrical conductivity is much lower than that of copper. The higher losses in the rotor may lead to the need to rearrange the rotor cooling or to limit the power output to prevent the rotor from overheating. In Case 3, the rotor without copper enables a much higher rotational speed than in the two other cases, where the limiting factor is the structural strength of the copper end ring. In Case 3, this problem arises only at higher speed when the applied steel material meets its strength limitations. According to preliminary analyses, the machine could be run at $16000 \mathrm{~min}^{-1}$ without any major design revisions of the solid-steel rotor (as the case 1 and case 2 are limited to $12000 \mathrm{~min}^{-1}$ ).

\section{CONCLUSIONS}

In the $2 \mathrm{MW}$ case, the electromagnetic efficiency was reduced from $96.16 \%$ by $0.41 \%$ when the copper squirrel cage was replaced with rotor core slits. In the slitted-rotor machines, the efficiency with copper end rings is $95.75 \%$ and without copper end rings $95.70 \%$, i.e., the copper end rings improve the slitted rotor machine efficiency by $0.05 \%$. In the case studied, the rotor without copper end rings could be operated at $35 \%$ higher speed and still lead to a well operating machine from the mechanical perspective. When designing new highspeed machines, the one-piece rotor construction is appealing at least in the prototype because the risk of rotor failure is low. The achieved efficiency is lower than what could be achieved with the more complicated constructions. However, those structures need well-proven manufacturing technologies and the manufacturer's specific knowledge in manufacturing complicated solid rotors. In practice, the rotor of a high-speed machine in the megawatt range can be designed in a step-bystep manner starting with a simple solid steel rotor. Later the 
rotor can be further developed by adding first the copper end rings and then a squirrel cage in the rotor to minimize the design risks.

\section{REFERENCES}

[1] D. Gerada, A. Mebarki, N. L. Brown, C. Gerada, A. Cavagnino, and A. Boglietti. High-speed electrical machines: Technologies, trends, and developments. IEEE Transactions on Industrial Electronics, 61(6):29462959, June 2014.

[2] H. Bleuler, M. Cole, P. Keogh, R. Larsonneur, E. Maslen, Y. Okada, G. Schweitzer, and A. Traxler. Magnetic Bearings: Theory, Design, and Application to Rotating Machinery. Springer Science \& Business Media, Berlin Heidelberg, 1st edition, 2009.

[3] J. Pyrhönen, J. Nerg, P. Kurronen, and U. Lauber. High-speed, 8 $\mathrm{mw}$, solid-rotor induction motor for gas compression. In 2008 18th International Conference on Electrical Machines, pages 1-6, Sept 2008.

[4] J. Pyrhönen, J. Nerg, P. Kurronen, and U. Lauber. High-speed highoutput solid-rotor induction-motor technology for gas compression. IEEE Transactions on Industrial Electronics, 57(1):272-280, 2010.

[5] D. Gerada, A. Mebarki, N. L. Brown, K. J. Bradley, and C. Gerada. Design aspects of high-speed high-power-density laminated-rotor induction machines. IEEE Transactions on Industrial Electronics, 58(9):4039_ 4047, Sep. 2011.

[6] N. Uzhegov, E. Kurvinen, J. Nerg, J. Pyrhönen, J. Sopanen, and S. Shririnskii. Multidisciplinary design process of a 6-slot 2-pole highspeed permanent-magnet synchronous machine. IEEE Transactions on Industrial Electronics, 63(2):784-795, Feb 2016.

[7] J. Barta, N. Uzhegov, P. Losak, C. Ondrusek, Mach M., and J. Pyrhönen. Squirrel cage rotor design and manufacturing for high-speed applications. IEEE Transactions on Industrial Electronics, pages 1-10, 2018.

[8] T. Mauffrey, J.-F. Pradurat, L. Durantay, and J Fontini. Comparison of 5 different squirrel cage rotor designs for large high speed induction motors. In PCIC Europe (PCIC EUROPE), 2013 Conference Record, pages 1-9. IEEE, 2013.

[9] F. Findik. Recent developments in explosive welding. Materials \& Design, 32(3):1081 - 1093, 2011.

[10] J. Pyrhönen, J. Nerg, A. Mikkola, J. Sopanen, and T. Aho. Electromagnetic and mechanical design aspects of a high-speed solid-rotor induction machine with no separate copper electric circuit in the megawatt range. Electrical Engineering, 91(1):35, Apr 2009.

[11] T. Aho. Electromagnetic design of a solid steel rotor motor for demanding operation environments. $\mathrm{PhD}$ thesis, Lappeenranta University of Technology, 2007.

[12] J. Pyrhönen, T. Jokinen, and V. Hrabovcová. Design of Rotating Electrical Machines. John Wiley \& Sons, United Kingdom, 1st edition, 2009.

[13] C. Di, I. Petrov, J. J. Pyrhönen, and X. Bao. Unbalanced magnetic pull compensation with active magnetic bearings in a $2 \mathrm{mw}$ high-speed induction machine by fem. IEEE Transactions on Magnetics, 54(8):113, Aug 2018.

[14] N. Amati and E. Brusa. Vibration condition monitoring of rotors on amb fed by induction motors. In 2001 IEEE/ASME International Conference on Advanced Intelligent Mechatronics. Proceedings (Cat. No.01TH8556), volume 2, pages 750-756 vol.2, July 2001. 